\title{
Development of a Mesoporous Silica-Supported Layered Double Hydroxide Catalyst for the Reduction of Oxygenated Compounds in E. grandis Fast Pyrolysis Oils
}

\author{
Danya Carla Maree *(D) and Mike Heydenrych (D) \\ Department of Chemical Engineering, University of Pretoria, Pretoria 0002, South Africa; \\ mike.heydenrych@up.ac.za \\ * Correspondence: danyacmaree@gmail.com; Tel.: +27-765-826-392
}

Citation: Maree, D.C.; Heydenrych, M. Development of a Mesoporous Silica-Supported Layered Double Hydroxide Catalyst for the Reduction of Oxygenated Compounds in E. grandis Fast Pyrolysis Oils. Catalysts 2021, 11, 1527. https:// doi.org/10.3390/catal11121527

Academic Editor: Claudia Carlucci

Received: 13 November 2021 Accepted: 13 December 2021 Published: 15 December 2021

Publisher's Note: MDPI stays neutral with regard to jurisdictional claims in published maps and institutional affiliations.

Copyright: (c) 2021 by the authors. Licensee MDPI, Basel, Switzerland. This article is an open access article distributed under the terms and conditions of the Creative Commons Attribution (CC BY) license (https:// creativecommons.org/licenses/by/ $4.0 /)$.

\begin{abstract}
Biomass fast pyrolysis oil is a potential renewable alternative to fossil fuels, but its viability is constrained by its corrosiveness, low higher heating value and instability, caused by high oxygenate concentrations. A few studies have outlined layered double hydroxides (LDHs) as possible catalysts for the improvement of biomass pyrolysis oil characteristics. In this study, the goal was to reduce the concentration of oxygen-rich compounds in E. grandis fast pyrolysis oils using CaAl- and MgAlLDHs. The LDHs were supported by mesoporous silica, synthesised at different pHs to obtain different pore sizes ( 3.3 to $4.8 \mathrm{~nm}$ ) and surface areas (up to $600 \mathrm{~m}^{2} / \mathrm{g}$ ). The effects of the support pore sizes and use of LDHs were investigated. GC/MS results revealed that MgAl-LDH significantly reduced the concentrations of ketones and oxygenated aromatics in the electrostatic precipitator oils and increased the concentration of aliphatics. CaAl-LDH had the opposite effect. There was little effect on the oxygenate concentrations of the heat exchanger oils, suggesting that there was a greater extent of conversion of the lighter oil compounds. Bomb calorimetry also showed a marked increase in higher heating values (16.2 to $22.5 \mathrm{MJ} / \mathrm{kg}$ ) in the electrostatic precipitator oils when using $\mathrm{MgAl}-\mathrm{LDH}$. It was also found that the mesoporous silica support synthesised at a $\mathrm{pH}$ of 7 was the most effective, likely due to the intermediate average pore width $(4 \mathrm{~nm})$.
\end{abstract}

Keywords: biofuels; pyrolysis; catalysis; layered double hydroxides; nanostructured materials; porous materials

\section{Introduction}

The US Energy Information Administration predicts that the global consumption of liquid fuels will rise by $28 \%$ by 2040 , due to an increase in population and industrial expansion [1]. Due to concerns over meeting the world's future energy demands, there is an increased drive to find more sustainable liquid fuel resources. One resource which is a promising biofuel feedstock due to its renewability and low greenhouse emissions is biomass [2]. Woody biomass can be converted to pyro-oil via a process called fast pyrolysis, in which the feedstock is heated to above $400{ }^{\circ} \mathrm{C}$, at a heating rate of more than $1000{ }^{\circ} \mathrm{C} / \mathrm{s}$, in an inert atmosphere [3]. The oils produced contain a variety of chemicals that can be separated and sold for value, refined in petrochemical refineries, or combusted as low-grade fuels for various applications [4].

The most prominent challenge in the manufacturing of pyrolysis oil from woody biomass is the chemical complexity of the oils produced [5]. Wood is composed of cellulose, hemicellulose and lignin, with each of these being composed of a high oxygen content [6]. During pyrolysis, these three units primarily convert into oxygenated compounds, such as organic acids, aldehydes, ketones, alcohols, esters, etc., constituting a significant fraction of the resultant pyro-oils [7]. Due to the presence of carbon-oxygen double bonds in these functional groups, the oils are corrosive, polar and susceptible to thermal degradation [3]. More notably, high oxygen content gives the oils heating values which are approximately 
half that of conventional liquid fuels [8]. This is motivated by the fact that the most important route to improving the use of the oil as a fuel and biorefinery feedstock is reducing its oxygen content. Increased pyrolysis oil oxygen content was found to be linked to a decrease in HHV and increase in viscosity over increased storage time [9,10]. Pyrolysis oils are also corrosive as a result of a high concentration of carbonyl bonds, and the instability of these bonds are also responsible for the change in the chemical composition of the oil over time [11]. For these reasons, high oxygen content also creates limitations and concerns in the design of biorefinery processes, especially regarding economic feasibility and risks [12].

One way to improve the quality of biomass fast pyrolysis bio-oils is through the use of an effective catalyst. In a thermochemical process such as fast pyrolysis, the catalyst needs to be thermally stable and have adequate surface area and porosity [13]. Additionally, the selectivity of pyrolysis products varies with catalyst pore size and chemical properties of the active sites [14]. When pore sizes are too small, larger molecules undergo catalytic conversion on external sites of the catalyst, where catalytic sites are considerably fewer and weaker, producing more undesired products in the heavier fractions [15]. When they are too large, there may be more oxygenated products because of fewer overall catalytic sites [16]. Therefore, the ability to tune the morphologies of these materials is of interest in catalysis. There are a number of minerals and nanostructured materials known for their abilities to improve pyrolysis products, including zeolites [17], mesoporous aluminosilicates [18] and alkaline compounds [19]. A nanostructured material that has gained recent interest in biomass pyrolysis due to deoxygenation capabilities is layered double hydroxides (LDHs) [20]. LDHs are a group of anionic clay compounds consisting of layers of metal hydroxides with negatively charged ions and water molecules in the interlamellar spaces. LDHs have the formula $\left[M_{x-1}^{2+} N_{x}^{3+}(\mathrm{OH})_{2}\right]^{x+}\left(A^{m-}\right)_{x / m} \cdot n H_{2} \mathrm{O}^{X-}$, where $\mathrm{M}, \mathrm{N}$ and A are $2+$ metal ions, $3+$ metal ions and 1-ions, respectively, and $\mathrm{x}$ and $\mathrm{m}$ define the ratios of the respective ions [21]. The chemical and physical behaviours, molar masses, charge densities and equivalent surface areas of LDHs are adjustable based on the $\mathrm{M}^{2+}$ and $\mathrm{M}^{3+}$ ions used, the ratios of these ions and the choice of interlamellar anions. LDHs have been reported to facilitate oxygen-removing reactions such as aldol condensation [22] and decarbonylation [23]. LDHs that are of interest to this study are CaAl-LDH, due to its reported aldol condensation ability [24], and MgAl-LDH, due to its popularity in catalytic biomass pyrolysis studies.

Another consideration is the catalyst support material. The catalyst support considered in this study is mesoporous silica, due to its high surface area per unit mass $\left(500 \mathrm{~m}^{2} / \mathrm{g}\right)$ [25] and the ability to control its morphology during synthesis [26]. Other literature has reported the use of MgAl- and CaAl-LDHs, but without the use of a mesoporous silica support [27]. Core-shellstructured mesoporous silica-supported $\mathrm{MgAl}-\mathrm{LDH}$ has previously been manufactured, but this method uses a surfactant to obtain its structure and was not investigated for biomass valorisation [28]. Another study has reported the use of tunable mesoporous silica supports for glycerol transesterification [29], but there was also little relation to biomass pyrolysis. There is a need to investigate the use of mesoporous silica-supported LDH for the reduction in oxygen content in biomass fast pyrolysis oils, because of the tunability of the support pore sizes. Producing the catalyst support through sol-gel synthesis, instead of through the combination of mesoporous silica powder and the active catalyst using a binder chemical, has the advantage of embedding the catalyst within the silica matrix. This, and the absence of a binder, may also increase the support total surface area. These two qualities can be seen in a graphical model of the comparison between the two catalyst support production methods, shown in Figure 1. 

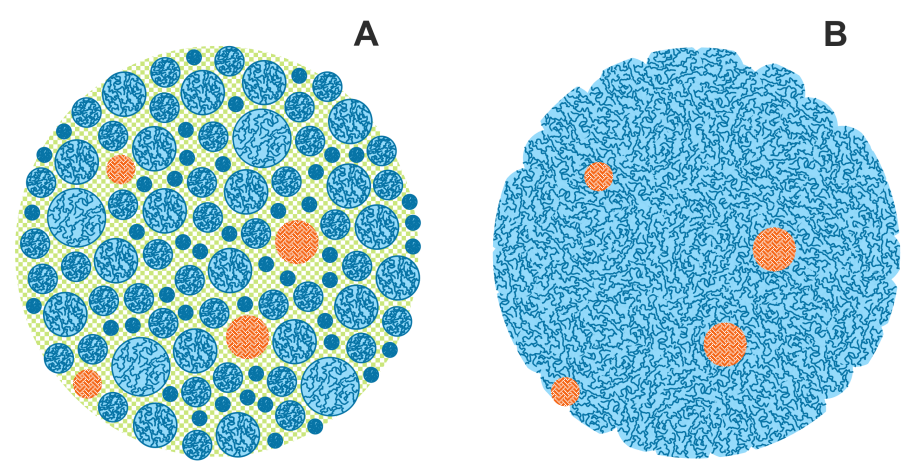

Figure 1. Visual comparison between (A) catalyst support produced by combining mesoporous silica powder and active catalyst powder with a binder and (B) mesoporous silica catalyst support produced via sol-gel synthesis.

The morphology of mesoporous silica is sensitive to its reaction conditions. This is as a result of the two mechanisms that occur during the polymerisation reaction to form mesoporous silica, namely condensation (the combination of silicate ions to form siloxane chains) and hydrolysis (the termination of silicate ions to form silanol groups) [30]. The rates of the respective reaction mechanisms are dependent on the synthesis $\mathrm{pH}$. At low $\mathrm{pH}$, a hydrogen atom is donated by the $\mathrm{SiO}$ or $\mathrm{SiOH}$ oxygen atom to form a stable leaving group such as water or alcohol in a hydrolysis reaction. At low $\mathrm{pH}$, a hydroxide ion (during hydrolysis, formed by deprotonation of a water molecule) or a $\mathrm{SiO}$ ion (during condensation, also formed via deprotonation) bonds to the $\mathrm{Si}$ atom of a Si-OR group to form a negatively charged ion. When the mixture $\mathrm{pH}$ is lower, more $\mathrm{Si}-\mathrm{OH}$ (silanol) groups are produced by this mechanism, because hydrolysis is favoured. This results in the formation of more new monomers. When the $\mathrm{pH}$ is higher, these silanol groups are more readily used in condensation reactions, forming more siloxane groups and thus longer branches. Therefore, siloxane bonds are more readily broken. On a three-dimensional scale, polymerisation begins with the creation of cyclic particles, which act as nuclei. At high $\mathrm{pH}$, the network continues to grow around a nuclei, and at low $\mathrm{pH}$, more nuclei are created which agglomerate. The gel morphology thus changes with $\mathrm{pH}$. This results in varying material properties, including surface areas and pore sizes [31]. Although silica has been reported to show some catalytic activity as a result of weak acidic sites [5], its effect on pyrolysis products is small, and it can therefore be used as a catalyst support to investigate the catalytic effects of LDHs. The variation in the product distribution of lignocellulosic biomass fast pyrolysis oils, with the use of LDH-doped mesoporous silica catalyst synthesised at different $\mathrm{pHs}$, can thus be assessed to find the optimal mesoporous silica catalyst support for LDHs in similar systems.

\section{Materials and Methods}

\subsection{Materials}

Materials for catalyst development included sodium silicate pentahydrate and sulfuric acid purchased from Chem Lab Supplies (Johannesburg, South Africa), MgAl-LDH with a 2:1 Mg/Al ratio with $\mathrm{CO}_{3}^{-}$interlamellar ions sourced from the Institute of Applied Materials at the University of Pretoria (Pretoria, South Africa) and CaAl-LDH with a 2:1 Ca/ Al ratio with $\mathrm{CO}_{3}^{-}$interlamellar ions sourced from Greenfield Additives (Pretoria, South Africa). Mixed E. grandis waste chips were sourced from SAPPI South Africa.

\subsection{Catalyst Preparation}

The CaAl- and MgAl-LDHs were sieved to below $32 \mu \mathrm{m}$. A sodium silicate solution was prepared by mixing $70 \mathrm{~g}$ of sodium silicate pentahydrate with $725 \mathrm{~g}$ of deionised water 
and stirred vigorously using a magnetic hotplate stirrer until it was dissolved. Amounts of $0.4 \mathrm{~g}, 1 \mathrm{~g}$ or $2 \mathrm{~g}$ of sieved LDH were added and the mixture was stirred vigorously for $5 \mathrm{~min}$ to ensure an even suspension; while stirring vigorously and monitoring the $\mathrm{pH}$, a 1:4 solution of sulfuric acid was slowly added to the mixture. At a $\mathrm{pH}$ of around 9.4, the mixture began to polymerise and was stirred until a smooth slurry was formed. Acid was then added slowly until pHs of 9, 7 and 5 were achieved, storing thirds of the slurry in Schott bottles at the respective pHs. The slurries were stored for $30 \mathrm{~min}$ and then filtered and washed 5 times with deionised water. The paste-like slurries were stored in open tins to air dry in a temperature- and humidity-controlled laboratory for 4 days, with five rounds of washing with deionised water taking place every second day to remove remaining water-soluble salts.

Overall, 7 catalysts were produced: 10\% MgAl-LDH supported by mesoporous silica synthesised at $\mathrm{pHs}$ of 5, 7 and 9, 10\% percent CaAl-LDH supported by mesoporous silica synthesised at $\mathrm{pHs}$ of 5,7 and 9 , and mesoporous silica reference catalyst containing no $\mathrm{LDH}$, synthesised at a $\mathrm{pH}$ of 7 . On the 4th day of drying, the slightly soft gels were broken into small sizes (approximately $4 \mathrm{~mm}$ ), placed on $3 \mathrm{~mm}, 1.5 \mathrm{~mm}$ and $0.5 \mu \mathrm{m}$ sieves stacked on one another, and the sieves were secured on a rotary shaker. The shaker was operated at $290 \mathrm{rpm}$ for one minute or until the gel pellets were roughly spherical. The pellets were then set to air dry in the laboratory until completely hardened and stored in containers to await characterisation.

\subsection{Catalyst Characterisation}

\subsubsection{Scanning Electron Microscopy}

A small amount of powdered sample, sieved to below $75 \mu \mathrm{m}$, was pressed onto doublesided tape and the excess was blown off using a high-pressure nitrogen nozzle. Each piece of sample tape was pressed onto a metal plate and coated with carbon. The coated plate was placed in a Zeiss 540 Ultra FEGSEM. Images were captured at various zoom and focus settings.

\subsubsection{Basicity Measurement}

LDH catalyst basic sites were determined using the benzoic acid titration method [32] An amount of $1.5 \mathrm{~g}$ of solid catalyst was mixed with $20 \mathrm{~mL}$ of methanol containing $0.6 \mathrm{~g}$ of dissolved phenolphthalein indicator, which is colourless below a pH of 8.2, and stirred continuously. A $0.01 \mathrm{M}$ solution of benzoic acid was dissolved in methanol and used as the titrant. The addition of the titrant was carried out until there was no pink colour remaining in the suspension. The amount of titrant required to neutralise the catalyst sample was used to calculate the basic site concentration of the catalyst.

\subsubsection{Nitrogen Physisorption}

A Micromeritics TriStar II Plus BET Surface Area Analyser was used for nitrogen physisorption testing. Each set of catalyst particles was sieved to between $0.8 \mathrm{~mm}$ and $1.2 \mathrm{~mm}$, the size range required for the spouted bed reactor. Approximately $2.5 \mathrm{~mL}$ of each sample was placed in a BET analyser tube. The tubes were placed in the degasser at $110{ }^{\circ} \mathrm{C}$ and under vacuum until a full vacuum was established (approximately $10 \mathrm{~h}$ ) to remove water, volatiles and organic impurities. The tubes were then connected to the analyser, and a holder containing liquid nitrogen was placed over the tubes. Weighing of the tubes took place before sample addition, after sample addition and after degassing. The instrument software was then used to run the analysis, and the BET surface areas and BJH adsorption average pore diameters were determined using the software. Samples synthesised under the same conditions were tested in triplicate to ensure repeatability of data.

\subsubsection{X-ray Diffraction (XRD)}

X-ray diffraction was carried out at the University of Pretoria's Geology Department. A PANalytical $X^{\prime}$ Pert Pro powder diffractometer in $\theta-\theta$ configuration with an $X^{\prime}$ Celerator 
detector and variable divergence was used for analysis. The ICSD database was used to identify the mineralogy using the X'Pert Highscore Plus software (Version 5.0, Malvern Panalytical, Malvern, UK).

\subsection{Fast Pyrolysis}

\subsubsection{Reactor Preparation}

Mixed E. grandis sawdust sieved to between $150 \mu \mathrm{m}$ and $300 \mu \mathrm{m}$ was dried in a convection oven at $105{ }^{\circ} \mathrm{C}$ for one hour. A tail-gas recirculation fast pyrolysis reactor, as shown in Figure 2, was used to investigate the effects of each catalyst. To prepare the reactor system, the piping and process equipment internal surfaces were cleaned using acetone and soap water. Both $250 \mathrm{~mL}$ and $150 \mathrm{~mL}$ Schott bottles were screwed onto the oil collection ports of the heat exchanger and electrostatic precipitator (ESP), respectively. The reactor base was screwed open and the previous heat transfer medium and/or catalyst particles were allowed to pour out and were stored, after which, the reactor base was screwed closed. A 1:4 ratio of catalyst particles to heat transfer medium (sand) totalling $100 \mathrm{~mL}$, both of which were sieved to between $0.8 \mathrm{~mm}$ and $1.2 \mathrm{~mm}$, were poured into the top of the reactor, and the top of the reactor was closed. The pump was switched on to ensure that the reactor was fluidising, as indicated by a negligible pressure increase on the pressure gauge before the feed pipe. A flowmeter reading of at least $50 \mathrm{~L} / \mathrm{min}$ before the feed pipe was required. Soap water spray was used to ensure that the system was free of leaks. The reactor top and bottom heating elements were then switched on and set to $600{ }^{\circ} \mathrm{C}$, and the reactor was purged with nitrogen gas.

\subsubsection{Reactor Operation}

Once the temperatures had stabilised at $600{ }^{\circ} \mathrm{C}$, the nitrogen purge gas was closed and the ESP was switched on. The feed pipe was filled with the dried sawdust, screwed closed, and the downward tilt of the pipe was adjusted to approximately $45^{\circ}$. The pump was switched on, and the sawdust was allowed to fall into the process line via vacuum. The sawdust continued into the fluidised bed, where it was pyrolysed. The pyrolysis vapours flowed through the double pipe heat exchanger, where those vapours condensed at above $70{ }^{\circ} \mathrm{C}$ were collected in the $250 \mathrm{~mL}$ Schott bottle. Char was collected in the cyclone, which was located in the reactor disengagement zone. A small amount of fine char estimated at $3 \mathrm{~g}$ gathered in the piping between the reactor and the heat exchanger and was taken into account in yields calculations. The remaining condensable vapours travelled through the ESP and were collected in the $150 \mathrm{~mL}$ Schott bottle. Non-condensable gases travelled out of the gas purge line and through a ventilation line. Once the sawdust was depleted, as evidenced by no more smoke flowing into the $250 \mathrm{~mL}$ Schott bottle, the pump was switched off, the feed pipe was refilled and closed, and the pump was switched on. The process was repeated until a total of $100 \mathrm{~g}$ of sawdust had been used. In total, $100 \mathrm{~g}$ sawdust was used per run, and 3 runs were completed per catalyst to ensure repeatibility of data. Three runs without a catalyst were also completed to provide a reference.

\subsection{Analysis of Pyrolysis Oils}

\subsubsection{Fourier-Transform Infrared Spectroscopy (FTIR)}

A PerkinElmer FTIR spectrometer was used for the analysis. The FTIR software was used to run a background test, and a drop of oil sample was placed on the analyser crystal. The arm was placed over the crystal and fastened. Wavenumbers $4000 \mathrm{~cm}^{-1}$ through $400 \mathrm{~cm}^{-1}$ were analysed using the software, and this provided a spectrum of peaks. The respective peak intensities of each sample were compared to those of the reference samples (heat exchanger and ESP oils using no catalyst, and silica catalyst support). 


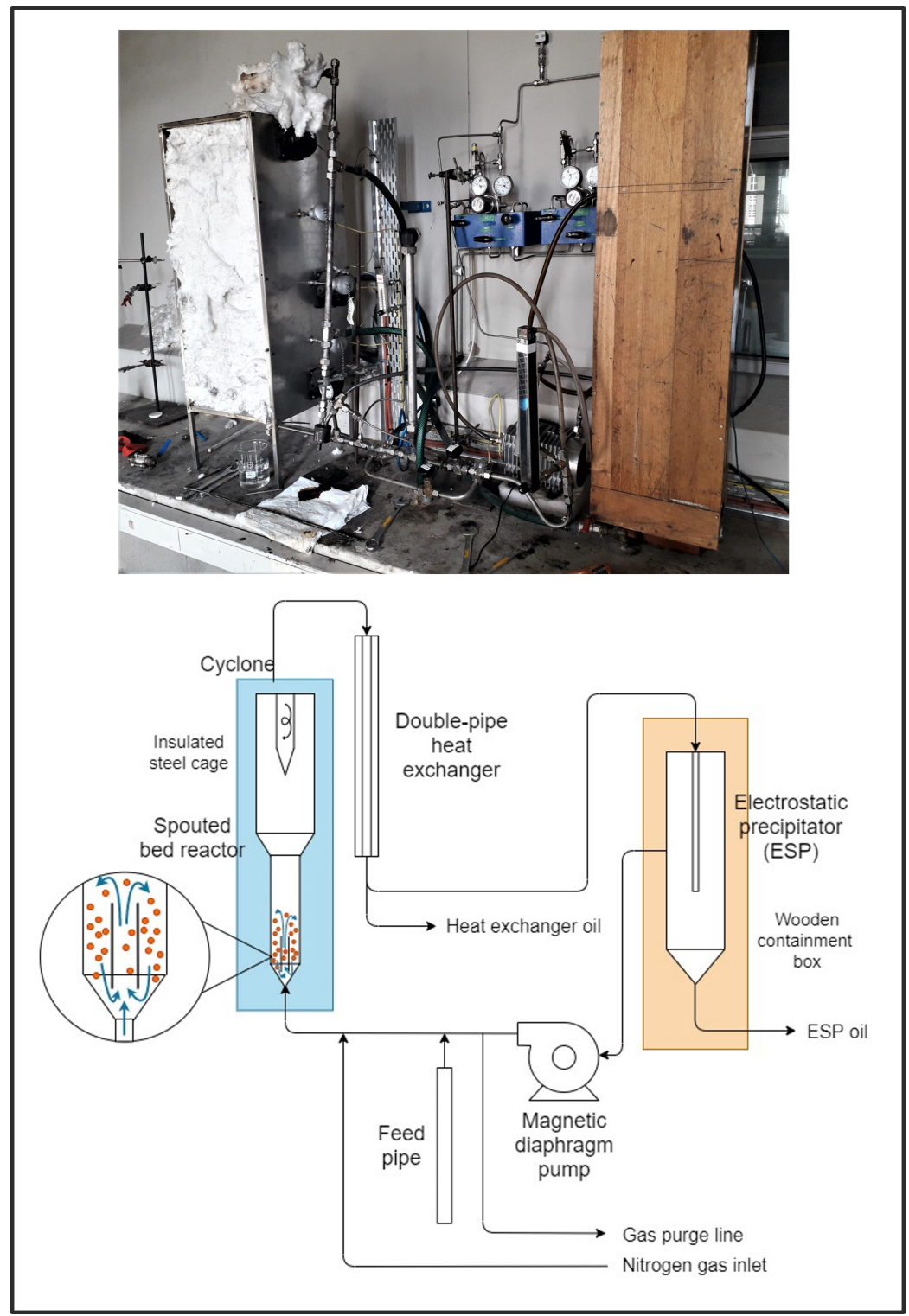

Figure 2. Photo and diagram of tail-gas recirculation spouted bed reactor.

\subsubsection{Gas Chromatography-Mass Spectrometry (GC/MS)}

ESP oils did not require sample preparation for GC/MS, as they were already in the organic phase. Organic constituents in the heat exchanger oils underwent liquid-liquid extraction using a 1:2 ratio by mass of oil to ethyl acetate, $15 \mathrm{~min}$ of vigorous stirring and two days of phase separation. The ESP oils and ethyl acetate phases of the heat exhanger oils were used for GC/MS analysis. GC/MS was performed on the pyrolysis oils using a PerkinElmer Clarus 600 Gas Chromatograph and a PerkinElmer Clarus 600T Mass Spectrometer. A sample around $2 \mu \mathrm{L}$ in size was injected into each sample cup, and the injector temperature was set to $250^{\circ} \mathrm{C}$. The initial oven temperature was set to $50{ }^{\circ} \mathrm{C}$ for $5 \mathrm{~min}$ and then rose to $250{ }^{\circ} \mathrm{C}$ over $10 \mathrm{~min}$, held at $250^{\circ} \mathrm{C}$ for a further $5 \mathrm{~min}$. Mass spectra were gathered in total ion current (TIC) mode for molar masses from 30 to 300 . Compounds were determined using the NIST11 library.

\subsubsection{Bomb Calorimetry}

The samples were prepared by mixing a 4:1 ratio of ESP oil samples with ethanol to aid combustion. A Parr Calorimeter 6200 was used with a 1104 Oxygen Combustion Bomb. The instrument water bucket was filled with the required amount of distilled water, and the 
sample was poured into a crucible and the mass of both the sample and the added ethanol was measured. A nichrome fuse wire was threaded through the instrument sample holder and through the sample, ensuring that the wire did not make contact with the surfaces of the crucible. After the holder was placed in the bomb, it was pressurised with oxygen at $3 \mathrm{MPa}$. The bomb was then placed in the water bucket, the wires were connected and the program was run. After running, the instrument determined the higher heating value (HHV) of the sample in $\mathrm{MJ} / \mathrm{kg}$, taking into account the energy released by the nichrome wire. The HHVs of the ethanol fractions were taken into account in the calculation of the final oil HHVs.

\section{Results and Discussion}

\subsection{Catalyst Characterisation}

\subsubsection{Scanning Electron Microscopy}

Figure 3 shows the morphology of LDH as well as flakes of LDH embedded in the catalyst support. The mesoporous silica has a rough but homogenous texture, while the LDH consists of relatively smooth, rounded flakes. It should be noted that the pores of the mesoporous silica support are several orders of magnitude smaller than what is visible in the figure. Before the LDH is suspended in the sol-gel, the flakes form agglomerates, as can be seen in the figure. Even if these agglomerates were large enough to be suitable for use in a fluidised bed reactor, they would be extxremely friable, resulting in the entrainment of flakes and clogging of the reactor. If the $\mathrm{LDH}$ powder was to be combined with a support such as diatomaceous earth powder, the flakes would still be too large to enter the mesopores. This would result in the LDH being adhered to the outer surfaces of the support particles, necessitating a binder chemical. Depending on the binder used, the catalyst could still be friable, or there could be a reduction in surface area as a result of the pores being filled by the binder. Figure 3B clearly shows how manufacturing the support using sol-gel synthesis as opposed to support powder and a binder is advantageous in this regard. The LDH flakes are directly embedded in the mesoporous silica matrix when the silicate solution polymerises. This means that the LDH flakes are less likely to come loose, the catalyst pore sizes can be tuned, a high surface area can be achieved and no binder is required.

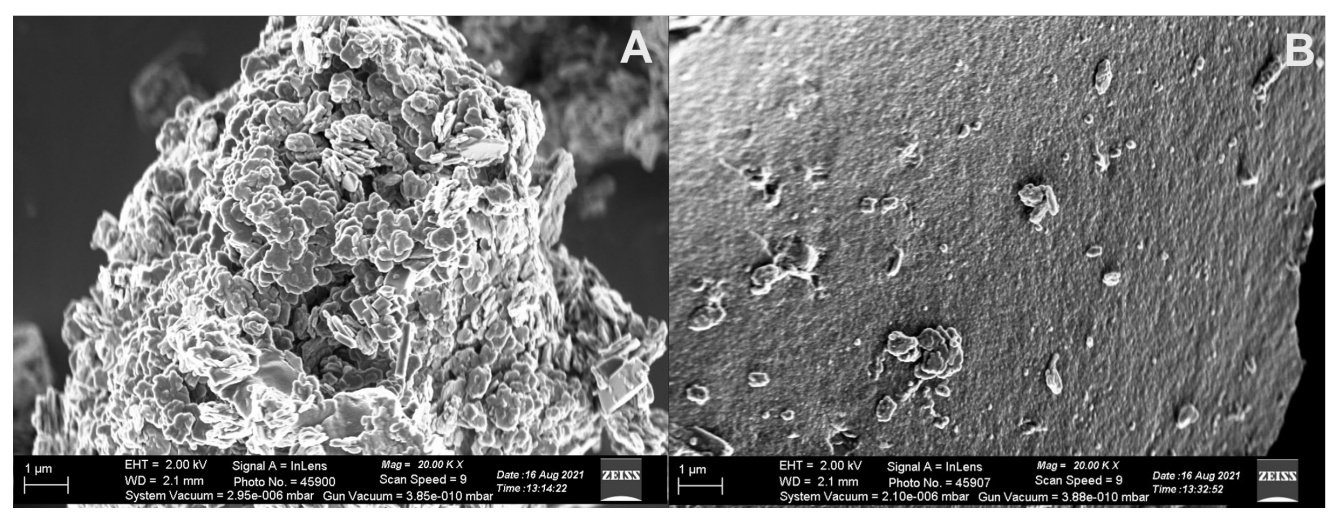

Figure 3. Scanning electron microscopy (SEM) images of catalyst materials: (A) A layered double hydroxide (LDH) particle, (B) LDH flakes embedded in mesoporous silica support.

\subsubsection{Basicity Measurement}

Pure MgAl-LDH and CaAl-LDH yielded basic site concentrations of 0.32 and $0.43 \mathrm{mmol} / \mathrm{g}$ catalyst, respectively, comparable to the literature-reported value range of 0.39 and 0.5 [33]. This confirms that the CaAl-LDH is the more basic of the two LDHs. The basicities of other representative heterogenous basic catalysts are $0.49,0.38,0.29$ and 0.3 for $\mathrm{CaO}$, aluminosilicate-supported platinum, palladium and ruthenium, respectively, [34]. Mesoporous zeolite, which has both acidic and basic sites, has a total basicity of $0.27 \mathrm{mmol} / \mathrm{g}$ catalyst [35]. The basicity of MgAl-LDH supported by mesoporous silica synthesised at a 
$\mathrm{pH}$ of 9 was $0.2 \mathrm{mmol} / \mathrm{g}$ catalyst, compared to those synthesised at pHs of 7 and 5, which resulted in values of 0.11 and $0.06 \mathrm{mmol} / \mathrm{g}$ catalyst, respectively. These values are lower than literature results of $0.53 \mathrm{mmol} / \mathrm{g}$ [29]. However, this is the basicity of mesoporous silica-supported $\mathrm{MgAl}-\mathrm{LDH}$ with the same $\mathrm{Mg} / \mathrm{Al}$ ratio and similar support BET surface area, but produced using a suspension of mesoporous silica powder rather than sol-gel synthesis. Although the nitrogen physisorption results showed an increase in surface area with decreasing synthesis $\mathrm{pH}$, the decrease in basic sites is likely due to the neutralisation of basic sites by protons during support sol-gel synthesis at increasing pHs. This was also observed for CaAl-LDH supported by mesoporous silica, with decreasing basicity values of $0.29,0.15$ and $0.07 \mathrm{mmol} / \mathrm{g}$ catalyst for synthesis $\mathrm{pHs}$ of 9,7 and 5 , respectively.

\subsubsection{Nitrogen Physisorption}

After the quantification of the BET surface area and BJH adsorption average pore diameter of each of the $10 \% \mathrm{LDH}$ catalyst samples, it was found that the average BET surfaces areas were $609.5,521.5$ and $380.8 \mathrm{~m}^{2} / \mathrm{g}$ for catalysts synthesised at $\mathrm{pHs}$ of 5,7 and 9, respectively. This is shown in Figure 4. The downward trend in surface area is contrasted by an upward trend in $\mathrm{BJH}$ average pore diameters, shown by values of 3.3, 4.0, and $4.8 \mathrm{~nm}$ for the respective synthesis pHs. This relationship is shown in Figure 4. The higher proportion of condensation reactions and thus silica chain growth at higher $\mathrm{pH}$, and lower proportion of hydrolysis reactions and thus silica branch formation at lower $\mathrm{pH}$, are likely to be contributing factors for the differing material characteristics.
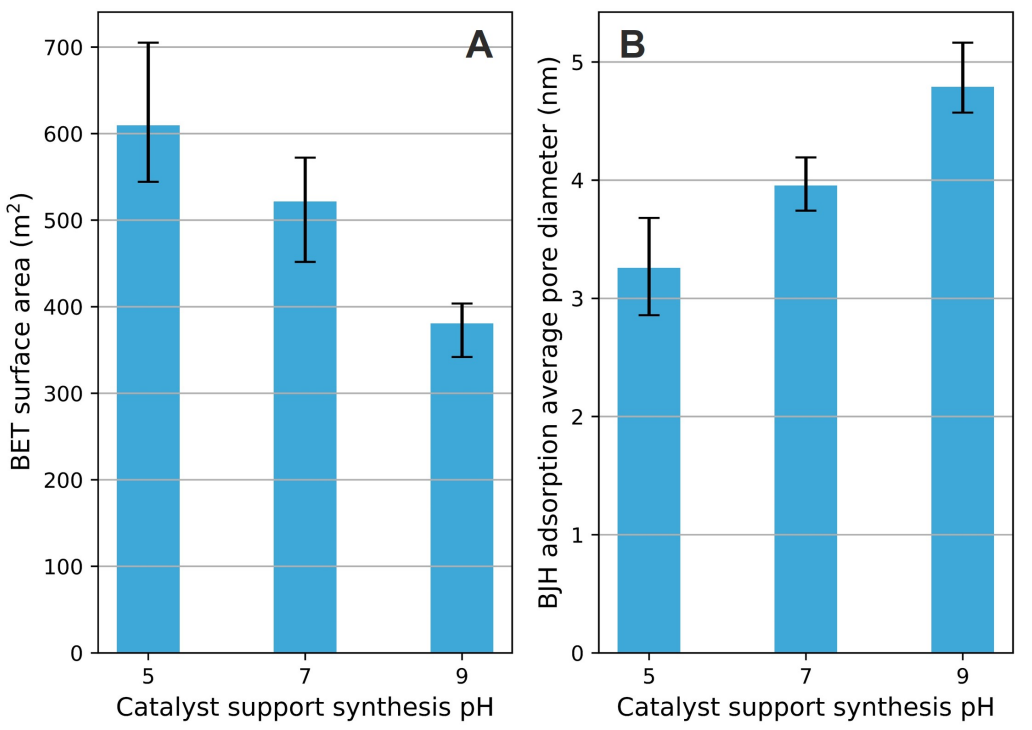

Figure 4. Nitrogen physisorption analysis, showing (A) catalyst support synthesis $\mathrm{pH}$ vs. BET surface area, and (B) catalyst support synthesis $\mathrm{pH}$ vs. $\mathrm{BJH}$ average pore diameter.

\subsubsection{X-ray Diffraction (XRD)}

XRD analysis was performed on each of the supported LDH samples, as well as the pure LDH catalysts. The results of this analysis is shown in Figure 5. Quantitative XRD confirmed that the MgAl-LDH is mainly composed of synthetic hydrotalcite (2:1 $\mathrm{Mg} / \mathrm{Al}$ ratio), and the CaAl-LDH is mainly composed of synthetic hydrocalumite (2:1 $\mathrm{Ca} / \mathrm{Al}$ ratio). The analysis also showed the presence of small amounts of calcite $\left(\mathrm{CaCO}_{3}\right)$, quartz $\left(\mathrm{SiO}_{2}\right)$ and katoite $\left(\mathrm{Ca}_{3} \mathrm{Al}_{2}\left(\mathrm{SiO}_{4}\right)^{3}-\mathrm{x}(\mathrm{OH})_{4 x}, \mathrm{x}=1.5-3\right)$. From the XRD graphs of the silica-supported LDH catalysts, the most significant observation is that there is little difference. In general, the large, broad peak is caused by the presence of amorphous silica (which is the main constituent in the catalyst support, as it is $\approx 90 \%$ of the catalyst mass). The major concern in the support synthesis was the formation of crystalline silica, or quartz, which is not porous. The XRD results confirm that if quartz is present, it is only present in 
trace amounts. Small peaks are visible for the respective LDHs. Trace amounts of sodium sulphate were also found, as it is formed as a side-product during the sol-gel synthesis. Sodium sulphate can behave as a catalyst, so the importance of washing the gels after synthesis is emphasised. Although the LDH peaks are small in comparison to those of the amorphous silica peaks, the LDH peaks appear to be larger in the catalysts supports synthesised at a $\mathrm{pH}$ of 9 . Like the basicity measurements, this could be due to a breakdown, and a loss in crystallinity, of the LDHs supported by silica synthesised at lower $\mathrm{pHs}$.
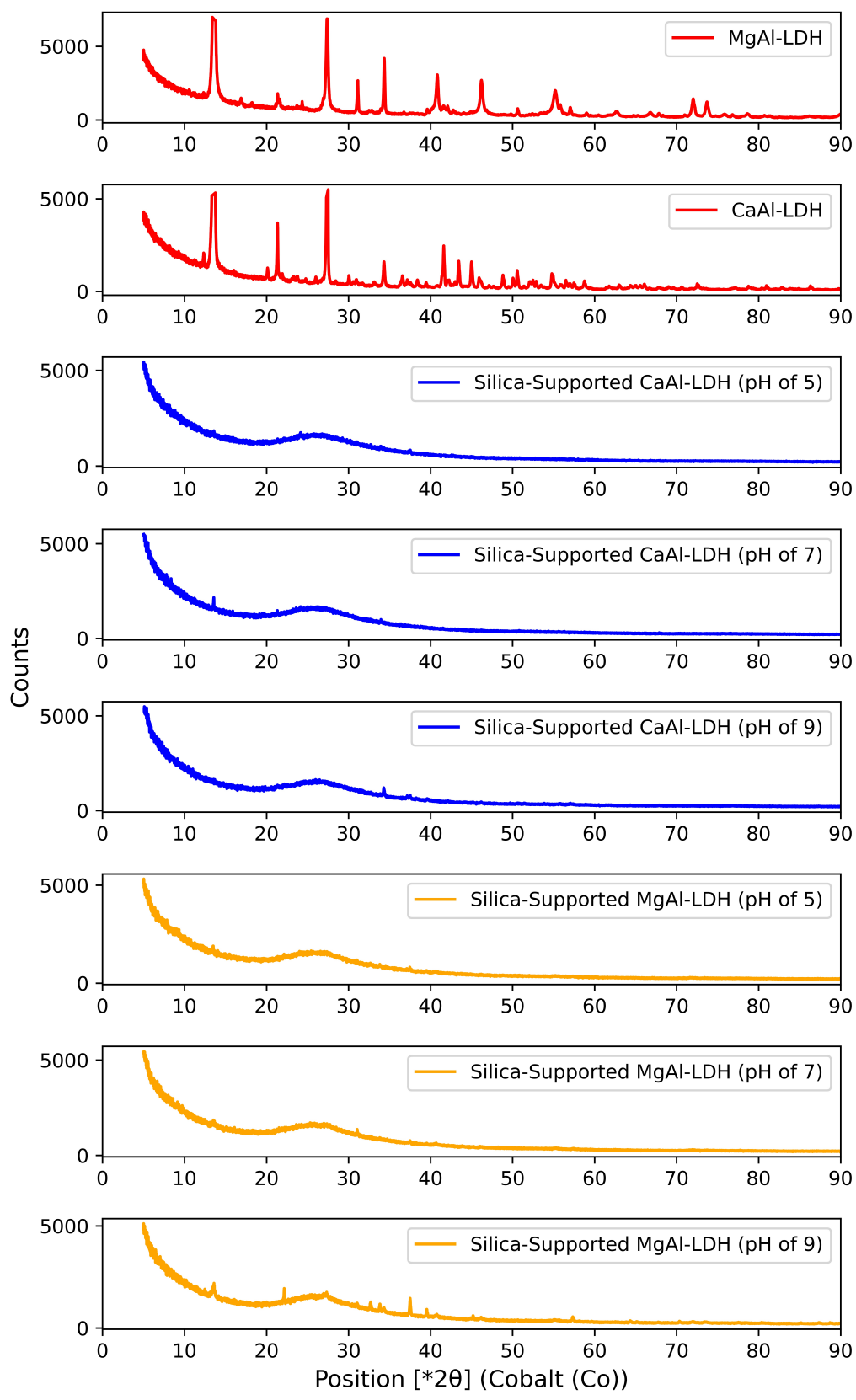

Figure 5. X-ray diffraction results for pure MgAl- and CaAl-LDH and LDHs produced with silica supports synthesised at the respective pHs of 5,7 and 9 .

\subsection{Catalytic Activity}

\subsubsection{Pyrolysis Products Distribution}

Figure 6 shows the change in oil, gas and char yields, as well as the change in heat exchanger and ESP oil yields, with the use of the different catalysts. The average total oil yield of runs without catalyst was $37.6 \%$, while that of runs with the catalyst support was 
$35.5 \%$. The total oil yields for MgAl-LDH catalysts were 32.9, 36.9 and $38.6 \%$ for a support synthesis pHs of 5, 7 and 9, respectively. CaAl-LDH catalysts produced higher total oil yields of $37.5,43.7$ and $47.2 \%$ for the respective support synthesis $\mathrm{pHs}$. The same trend was observed for the fractions of ESP oil that make up the total oil yields, with ESP oil portions of $25.7,30.3$ and $35.8 \%$ for increasing catalyst synthesis $\mathrm{pHs}$. The increase in yields for each type of LDH correspond to decreasing BET surface areas and increasing BJH average pore diameters.
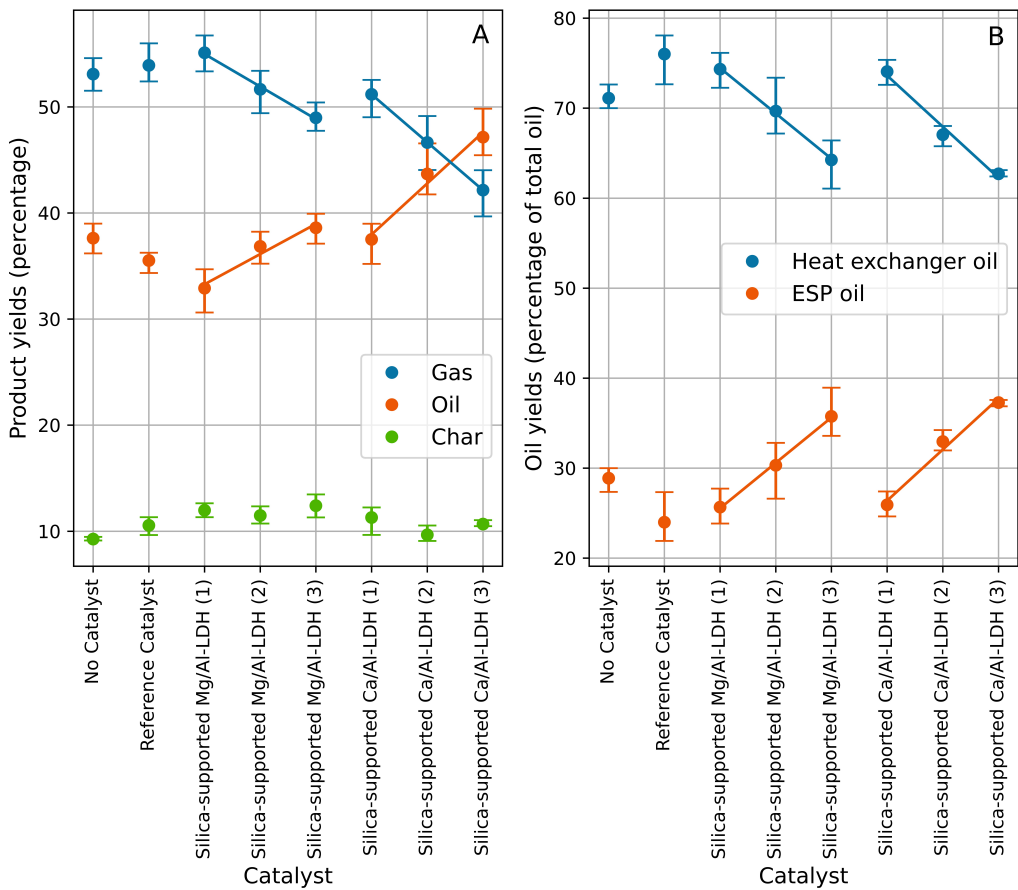

Figure 6. The changes in the pyrolysis product yields with the use of the different catalysts: (A) the change in total oil, gas and char fractions with change in catalyst, (B) the change in heat exchanger (HE) oil and electrostatic precipitator (ESP) oil fractions of the total oil product with change in catalyst.

\subsubsection{FTIR Spectra}

The most notable differences in the FTIR spectra, as shown in Figure 7, are in the peak around $3200 \mathrm{~cm}^{-1}$. With the peaks around $1600 \mathrm{~cm}^{-1}$, the intensities of these peaks are likely to be attributed to high water contents. There is a noticeable decrease in the peak intensity around $3200 \mathrm{~cm}^{-1}$ with the catalyst support alone compared to no catalyst, for both the heat exchanger and ESP oils. For the heat exchanger oils, the decrease in intensity is even more prominent for all three $\mathrm{MgAl}-\mathrm{LDH}$ catalysts, where the opposite effect is seen for the CaAl-LDH catalysts.

For the ESP oils, the intensities of the $3200 \mathrm{~cm}^{-1}$ peak of the MgAl-LDH catalysed oils lie between that of the catalyst support and no catalyst. The same is observed for the CaAl-LDH catalysed oils, but the peak intensities are larger. These results indicate that the catalyst support itself contributes to a significantly lower concentration of $-\mathrm{OH}$ stretching vibrations, likely to be indicative of water, but also partly because of carboxylic acids, alcohols and phenolic groups. This trend is evident in both the heat exchanger and ESP oils. Oils catalysed by MgAl-LDH further decreased these levels in the heat exchanger oils, but not the ESP oils. Oils catalysed by CaAl-LDH increased the concentration of -OH stretching vibrations in both the heat exchanger and ESP oils. For all three catalyst support synthesis $\mathrm{pHs}$ of each LDH catalyst, the results were similar.

Other changes in the heat exchanger oil FTIR spectra included an increase in the peak intensity around $1450 \mathrm{~cm}^{-1}$, indicating carbon double bond stretching such as those present in aromatic rings, as a result of the silica support. Doping of the support with $\mathrm{MgAl}-$ LDH increased the intensity of this peak, while CaAl-LDH decreased this peak. The same 
effect was observed for the peak around $1250 \mathrm{~cm}^{-1}$, indicating alkane deformation. In the ESP oils, the catalyst support and MgAl-LDH catalysts resulted in a decrease in the peak intensity around $1050 \mathrm{~cm}^{-1}$, indicating ethers and alcohols. This peak increased in intensity with the CaAl-LDH catalysts.

While there were noticeable differences in the peak intensities produced with LDHcatalysed oils, there was very little difference in the same LDHs with supports catalysed at different $\mathrm{pHs}$. This indicates that surface areas and average pore widths do not play a significant role in the sizes of $-\mathrm{OH}$ stretching peaks.
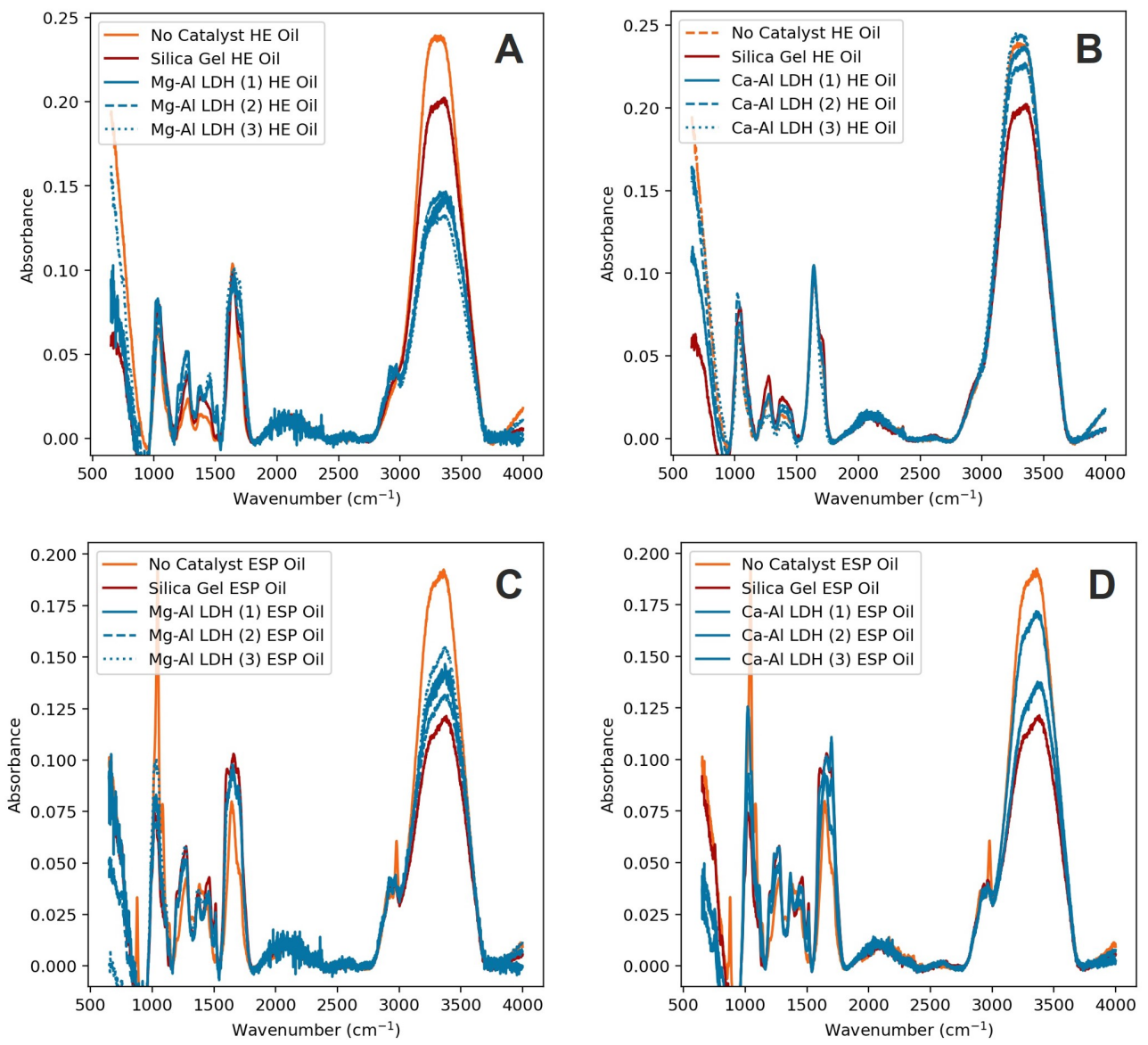

Figure 7. FTIR spectra of (A) the MgAl-LDH- and (B) CaAl-LDH-doped catalyst heat exchanger oils, and (C) the MgAl-LDH- and (D) CaAl-LDH-doped catalyst ESP oils.

\subsubsection{Gas Chromatography/Mass Spectrometry}

Figure 8 shows the effect of the reference catalyst (mesoporous silica support) on the compositions of the heat exchanger oil organic fractions and ESP oils in comparison to the uncatalysed oils. The results showed that there was a small amount of catalytic activity in the catalyst support alone. The heat exchanger oil organic fraction compositions in peak area percents showed a decrease in aliphatics from $6.9 \%$ to $3.1 \%$ with the use of the reference catalyst. There was a rise in oxygenates, such as non-cyclic ketones, aldehydes and esters including methyl glyoxal, isopropyl acetate and succinaldehyde, from $13 \%$ to $24.1 \%$. Carboxylic acids such as acetic and octanoic acids also rose from $7.2 \%$ to $18.8 \%$. The ESP oil compositions of aliphatics such as hexane and heptane, cyclic ethers and ketones such as furfural, 3-furaldehyde, butyrolactone and benzaldehyde, and non-oxygenated aromatics such as toluene, xylene and naphthalene were similar $(31.47 \%, 3.73 \%$ and $1 \%$, respectively). However, the support resulted in a small increase in branched aliphatics such as methyl-pentane and methyl-hexane (51.22\% to 54.47\%), a small decrease in oxygenated aromatics such as phenol, methyl-, dimethyl- and trimethyl- 
phenol $(10.27 \%$ to $8.47 \%)$, and a more notable increase in non-cyclic ketones such as acetone and hydrazinecarboxamide $(2.02 \%$ to $8 \%)$. These small catalytic effects are likely a result of the slightly acidic properties of exposed silanol groups present in the support. The overall effect of the silica support alone on the quantity of oxygenated compounds is very small. However, the silica support appears to favour the formation of heavier oxygenates, as evidenced by the larger proportion of oxygenates in the heat exchanger oil fractions.
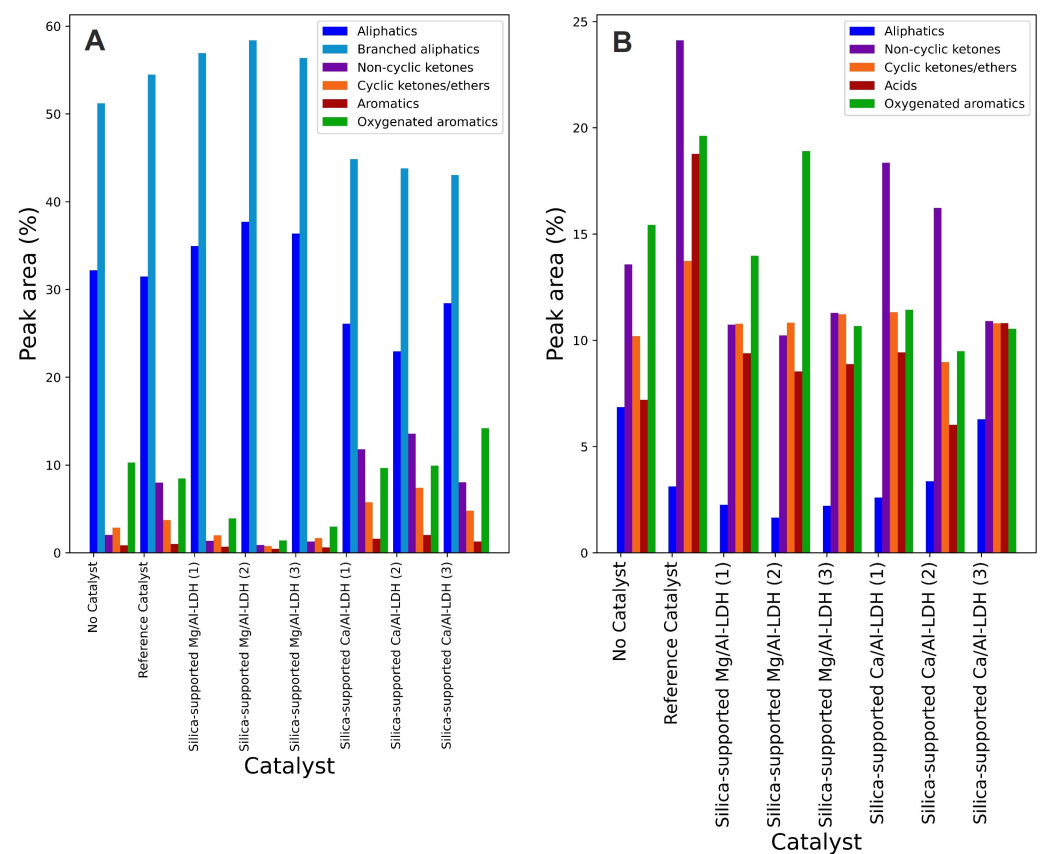

Figure 8. GC/MS analysis of (A) ESP oils and (B) heat exchanger oils produced by fast pyrolysis of E. grandis sawdust using different catalysts.

MgAl-LDH catalysts resulted in lower oxygenate compositions in the heat exchanger organic fractions compared to the reference catalyst, with a composition similar to that of the non-catalysed heat exchanger oils. The changes in compositions of the ESP oils are more apparent. The most notable change is the decrease in ketones, ethers, non-oxygenated and oxygenated aromatics throughout all three catalyst support synthesis $\mathrm{pHs}$. There was very little change in the compositions of the heat exchanger organic fractions throughout all three MgAl-LDH catalysts, except for an increase (to 18.9\%) in oxygenated aromatics in catalyst 2. All three MgAl-LDH catalysts also displayed an increase in aliphatics and branched aliphatics in the ESP oils. The catalyst synthesised at a $\mathrm{pH}$ of 7 appears to have the lowest amount of oxygenates $(3.06 \%)$ and aromatics $(0.46 \%)$, as well as the highest amount of aliphatics $(96.07 \%)$. MgAl-LDH catalysts synthesised at $\mathrm{pHs}$ of 5 and 9 contain almost identical compositions $(91.88 \%, 3.35 \%, 3.91 \%$ and $0.7 \%$ for aliphatics, ketones and ethers, oxygenated aromatics and non-oxygenated aromatics, respectively). The results for the MgAl-LDH catalysts show that the catalyst support synthesis $\mathrm{pH}$, and thus the catalyst pore width, plays a small role in the compositions of the oils produced. MgAl-LDH supported by mesoporous silica with an intermediate pore size of around $4 \mathrm{~nm}$ produces more heavy oxygenated aromatics and more light aromatics.

CaAl-LDH catalysts had the opposite effect on the ESP oils to the MgAl-LDH catalysts. The concentrations of aliphatics and branched aliphatics decreased $(26.09 \%$ and $44.85 \%$, respectively), while the concentrations of oxygenates and aromatics increased (27.23\% and $1.61 \%$, respectively). The increase in oxygenates as a result of CaAl-LDH compared to MgAl-LDH is likely as a result of the differences in acid-base properties between the two catalysts. CaAl-LDH contains stronger basic sites than MgAl-LDH [36]. An increased effect was also observed in the CaAl-LDH catalyst synthesised at a $\mathrm{pH}$ of 7 , 
similar but opposite to the effect noticed in the Mg-Al LDH catalyst. With the exception of higher non-cyclic ketones, aldehydes and esters compositions (above 15\%), the compositions of heat exchanger oil organic fractions did not vary significantly with the use of CaAl-LDH catalysts. This indicates that CaAl-LDH catalysts results in little change to the heavier fraction, but notable change to the lighter fraction.

There appeared to be a link between the catalyst basic sites concentrations and the FTIR and GC/MS results. Lower average ESP oil oxygenate concentrations $(4 \%)$ were produced using MgAl-LDH catalysts with basicity values between 0.1 and $0.2 \mathrm{mmol} / \mathrm{g}$ catalyst, while higher average ESP oil oxygenate concentrations (30\%) were produced using CaAl-LDH catalysts with basicity values between 0.1 and $0.3 \mathrm{mmol} / \mathrm{g}$ catalyst. The extent to which the catalyst $\mathrm{BJH}$ adsorption average pore diameters influenced the product compositions is unknown, but there does appear to be a link. Where it is expected that there would be fewer oxygenates in the ESP oils catalysed by MgAl-LDH supported by silica synthesised at a $\mathrm{pH}$ of 5 , due to a low basicity of $0.1 \mathrm{mmol} / \mathrm{g}$ catalyst, the oxygenate concentration is higher compared to the other MgAl-LDH-catalysed ESP oils. This is likely because of the small pore size $(3.3 \mathrm{~nm})$, reducing the catalytic conversion of medium-sized oxygen-rich organic compounds such as furfural and larger compounds such as levoglucosan (kinetic diameters of 0.55 and $6.7 \mathrm{~nm}$, respectively, [37]) due to diffusion limitations. Larger pore sizes $(4.0 \mathrm{~nm}$ and $4.8 \mathrm{~nm}$ ) are more likely to allow for increased diffusion of these molecules through the catalyst.

With the low organic fractions in the heat exchanger oils as a result of high water content, as well as the lack of useful GC/MS data for these fractions, there is not enough evidence from analysis of the heat exchanger oils to confirm catalytic activity. However, similar trends in the MgAl- and CaAl- LDHs, synthesis pHs and ESP oil compositions suggest that a catalyst support synthesis $\mathrm{pH}$ of 7 has the highest catalytic activity. A synthesis $\mathrm{pH}$ of 7 correlates to an intermediate BET surface area and pore size of around $520 \mathrm{~m}^{2} / \mathrm{g}$ and $4 \mathrm{~nm}$, respectively. The pronounced difference in the compositions of the ESP oils with the different catalysts, as well as the small difference in the composition of the heat exchanger oil fractions, suggests that the current catalyst pore size range is better suited for improving the lighter pyrolysis oil fractions as opposed to the heavier fractions. Larger pore sizes should be investigated to assess differences in the heavier fractions.

\subsubsection{Thermal Properties}

Dried E. grandis biomass was found to have an average HHV of $15.9 \pm 3.9 \mathrm{MJ} / \mathrm{kg}$. The HHV of the pyrolysis ESP oils without the use of a catalyst improved slightly to $16.2 \pm 2.2 \mathrm{MJ} / \mathrm{kg}$, and the reference catalyst produced ESP oils with a higher HHV of $19.6 \pm 1.9 \mathrm{MJ} / \mathrm{kg}$.

Use of the Mg-Al LDH catalysts yielded improved ESP oil HHVs of $21.7 \pm 0.9 \mathrm{MJ} / \mathrm{kg}$, $21.3 \pm 2.6 \mathrm{MJ} / \mathrm{kg}$ and $22.5 \pm 1.0 \mathrm{MJ} / \mathrm{kg}$, respectively. The increases may be as a result of larger aliphatics concentrations in the Mg-Al LDH catalysed ESP oils. However, there was no significant difference in the HHV values between the three mesoporous silica supports, likely as a result of the similar compositions.

All three Ca-Al LDH catalysts also produced lower ESP oil HHVs of $16.94 \pm 2.46 \mathrm{MJ} / \mathrm{kg}$, $15.7 \pm 0.8 \mathrm{MJ} / \mathrm{kg}$ and $15.0 \pm 0.4 \mathrm{MJ} / \mathrm{kg}$, respectively. The lower HHVs are likely due to the higher oxygenate concentration and higher FTIR -OH peaks.

The HHV values achieved for the E. grandis fast pyrolysis oils are lower than those reported for similar feedstocks at similar reaction conditions $(24.5 \mathrm{MJ} / \mathrm{kg})$ [38-40]. This is likely as a result of inefficiencies in the reactor system used in the investigation. The HHVs of pyrolysis oils can be improved using an optimised system and are expected to be higher as a result of MgAl-LDH catalysts.

\section{Conclusions}

Biomass fast pyrolysis oil is being investigated as an alternative to fossil fuels because it is renewable, and the combustion thereof produces less greenhouse gas emissions. Fast 
pyrolysis of $E$. grandis in a tail-gas recirculating spouted bed reactor system gives good pyro-oil yields, but the oils are unstable, corrosive and have low higher heating values as a result of elemental oxygen contents. This study investigated the use of mesoporous silica-supported layered double hydroxide catalysts to decrease the oxygen contents in pyro-oils produced in the fast pyrolysis of $E$. grandis sawdust in the aforementioned system.

Mesoporous silica catalyst supports with good surface areas (up to $600 \mathrm{~m}^{2} / \mathrm{g}$ ) were produced using sol-gel synthesis, and nitrogen physisorption tests showed an increase in $\mathrm{BJH}$ average adsorption diameters with an increase in sol-gel synthesis $\mathrm{pH}$. The effects of the different support pore sizes, as well as the LDH catalysts, on the pyrolysis oil products were studied. The LDHs embedded within the supports also appeared to experience some loss in structure and basicity as a result of the increased support synthesis $\mathrm{pHs}$, as demonstrated by XRD and basicity measurements. The results suggest that a link can be drawn between the support pore sizes and LDH basicity, and the concentration of oxygenated compounds in the oil.

FTIR analysis of the heat exchanger and electrostatic precipitator (ESP) oils showed that the MgAl-LDH catalysts appeared to reduce the intensities of $-\mathrm{OH}$ peaks mostly caused by high water contents, and CaAl-LDH catalysts had little influence on these peaks. The GC/MS results of the ESP and heat exchanger oils showed that the MgAl-LDH catalyst supported by mesoporous silica synthesised at a $\mathrm{pH}$ of 7 produced an ESP oil with the lowest oxygenate concentration, while the CaAl-LDH catalyst with a silica gel support synthesised at a $\mathrm{pH}$ of 7 yielded the greatest increase in the oxygen contents of ESP oils. The organic fraction compositions of the heat exchanger oils did not change significantly with the use of the LDH catalysts. This indicates that the catalyst supports were more suited for improving the lighter pyrolysis oil fractions than the heavier fractions, as a result of the pore widths. Future studies should be conducted on catalyst supports with larger pore sizes to see clearer differences in the heat exchanger oil fractions.

The higher heating values of ESP oils produced using MgAl-LDH catalysts supported by mesoporous silica were significantly higher than that of the non-catalysed oils. Overall, the contents of oxygenated compounds in the pyro-oils, and especially the ESP oils, were reduced by $\mathrm{MgAl}-\mathrm{LDH}$ and increased by $\mathrm{CaAl}-\mathrm{LDH}$. The mesoporous silica supports synthesised at a $\mathrm{pH}$ of 7 appeared to yield the greatest catalytic activities for both LDHs.

The study confirmed that synthetic mesoporous silica can be successfully used to support powdered catalysts for fast pyrolysis, and that $\mathrm{MgAl}-\mathrm{LDH}$ can be used to reduce oxygenated compounds in pyrolysis oils. Additionally, the morphology of the support can easily be tailored to the application, and the sol-gel synthesis method described does not require the use of a binder.

Author Contributions: Conceptualisation, M.H. and D.C.M.; methodology, D.C.M.; validation, M.H. and D.C.M.; formal analysis, D.C.M.; investigation, D.C.M.; resources, M.H.; data curation, D.C.M.; original draft preparation, D.C.M.; review and editing, M.H. and D.C.M.; visualisation, D.C.M.; supervision, M.H.; project administration, M.H.; funding acquisition, M.H. All authors have read and agreed to the published version of the manuscript.

Funding: The University of Pretoria provided the infrastructure and analytical equipment for this research.

Data Availability Statement: Data used in the study can be requested from the authors.

Acknowledgments: We would like to thank the Department of Chemical Engineering's Johan Labuschagne and Bianca Gevers for providing LDHs and technical advice thereof, Hanno Muire for assistance with nitrogen physisorption analysis, Shane Tabana for assistance with GC/MS, and the Department of Physics at the University of Pretoria for the use of the SEM.

Conflicts of Interest: The authors declare no conflict of interest. 


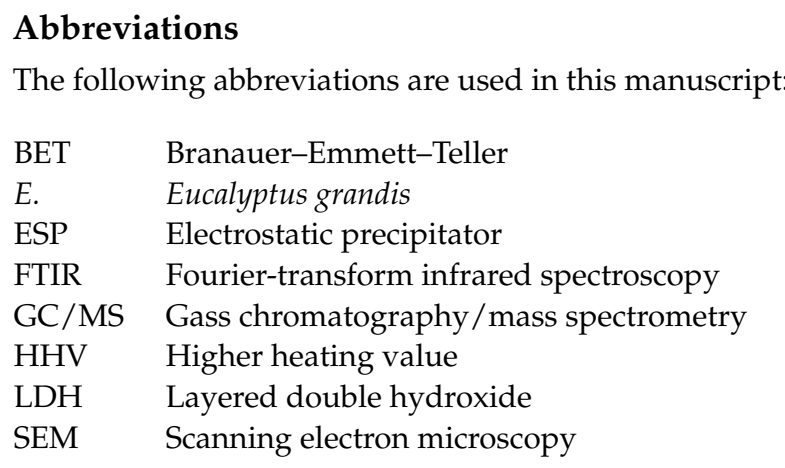

\section{References}

1. Stas, M.; Auersvald, M.; Kejla, L.; Vrtiska, D.; Kroufek, J.; Kubicka, D. Quantitative analysis of pyrolysis bio-oils: A review. Trends Anal. Chem. 2020, 126, 115857. [CrossRef]

2. Sun, T.L.; Lei, T.Z.; Li, Z.F.; Wang, Z.W.; Yang, S.H.; He, X.F.; Yue, Z.H.; Gao, Y.; Wu, Y.F.; Shi, X.G. Optimization of the Pyrolysis Carbonization of Various Corn Stalk Parts in a Rotating Bed Reactor Based on Energy Yield. J. Biobased Mater. Bioenergy 2018, 12, 378-386. [CrossRef]

3. Imran, A.; Bramer, E.A.; Seshan, K.; Brem, G. An overview of catalysts in biomass pyrolysis for production of biofuels. Biofuel Res. J. 2018, 20, 872-885. [CrossRef]

4. Ratnasari, D.; Yang, W.; Jönsson, P. Catalytic Pyrolysis of Lignocellulosic Biomass: The Influence of the Catalyst Regeneration Sequence on the Composition of Upgraded Pyrolysis Oils over a H-ZSM-5/Al-MCM-41 Catalyst Mixture. ACS Omega 2020, 5, 28992-29001. [CrossRef] [PubMed]

5. Behrens, M.; Cross, J.S.; Akasaka, H.; Ohtake, N. A study of guaiacol, cellulose and Hinoki wood pyrolysis with silica, $\mathrm{ZrO}_{2}$ \& $\mathrm{TiO}_{2}$ and ZSM-5 catalysts. J. Anal. Appl. Pyrolysis 2017, 125, 178-184. [CrossRef]

6. Chen, W.; Che, Q.; Li, S.; Liu, Z.; Yang, H.; Chen, Y.; Wang, X.; Shao, J.; Chen, H. Recent developments in lignocellulosic biomass catalytic fast pyrolysis: Strategies for the optimization of bio-oil quality and yield. Fuel Process. Technol. 2019, 196, 106180. [CrossRef]

7. Sun, T.; Li, Z.; Zhang, Z.; Wang, Z.; Yang, S.; Yang, Y.; Wang, X.; Liu, S.; Zhang, Q.; Lei, T. Fast corn stalk pyrolysis and the influence of catalysts on product distribution. Bioresour. Technol. 2020, 301, 122739. [CrossRef]

8. Katikaneni, S.P.R.; Adjaye, J.D.; Bakhshi, N.N. Performance of aluminophosphate molecular sieve catalysts for the production of hydrocarbons from wood-derived and vegetable oils. Energy Fuels 1995, 9, 1065-1078. [CrossRef]

9. Arun, J.; Gopinath, K.P.; SundarRajan, P.; Malolan, R.; AjaySrinivaasan, P. Hydrothermal liquefaction and pyrolysis of Amphiroa fragilissima biomass: Comparative study on oxygen content and storage stability parameters of bio-oil. Bioresour. Technol. Rep. 2020, 11, 100465. [CrossRef]

10. Tharifkhan, S.; Susaimanickam, A.; Mathimani, T.; Kathirvel, B.; Pugazhendhi, A. Upgrading of bio-oil from thermochemical conversion of various biomass-Mechanism, challenges and opportunities. Fuel 2020, 287, 119329. [CrossRef]

11. Czernik, S.; Bridgwater, T. Overview of Applications of Biomass Fast Pyrolysis Oil. Energy 2004, 18, 590. [CrossRef]

12. Yildiz, G.; Ronsse, F.; Van Duren, R.; Prins, W. Challenges in the design and operation of processes for catalytic fast pyrolysis of woody biomass. Renew. Sustain. Energy Rev. 2016, 57, 1596-1610. [CrossRef]

13. Deutschmann, O.; Knözinger, H.; Kochloefl, K.; Turek, T. Ullmann's Encyclopedia of Industrial Chemistry Heterogeneous Catalysis and Solid Catalysts, 2. Development and Types of Solid Catalysts. Ullmann's Encycl. Ind. Chem. 2011 , 17, 52. [CrossRef]

14. Carlson, T.; Tompsett, G.; Conner, W.; Huber, G. Aromatic Production from Catalytic Fast Pyrolysis of Biomass-Derived Feedstocks. Top. Catal. 2009, 52, 241. [CrossRef]

15. Hu, C.; Zhang, H.; Wu, S.; Xiao, R. Molecular shape selectivity of HZSM-5 in catalytic conversion of biomass pyrolysis vapors: The effective pore size. Energy Convers. Manag. 2020, 210, 112678. [CrossRef]

16. Bhoi, P.; Ouedraogo, A.; Soloiu, V.; Quirino, R. Recent advances on catalysts for improving hydrocarbon compounds in bio-oil of biomass catalytic pyrolysis. Renew. Sustain. Energy Rev. 2020, 121, 109676. [CrossRef]

17. Lappas, A.; Samolada, M.; Iatridis, D.; Voutetakis, S.; Vasalos, I. Biomass pyrolysis in a circulating fluid bed reactor for the production of fuels and chemicals. Fuel 2002, 81, 2087-2095. [CrossRef]

18. Iliopoulou, E.; Antonakou, E.; Karakoulia, S.; Vasalos, I.; Lappas, A.; Triantafyllidis, K. Catalytic conversion of biomass pyrolysis products by mesoporous materials: Effect of steam stability and acidity of Al-MCM-41 catalysts. Chem. Eng. J. 2007, 134, 51-57. [CrossRef]

19. Fahmi, R.; Bridgwater, T.; Darvell, L.; Jones, J.; Yates, N.; Thain, S.; Donnison, I. The effect of alkali metals on combustion and pyrolysis of Lolium and Festuca grasses. Fuel 2007, 86, 1560-1569. [CrossRef]

20. Song, Y.; Beaumont, S.; Zhang, X.; Wilson, K.; Lee, A. Catalytic applications of layered double hydroxides in biomass valorisation. Curr. Opin. Green Sustain. Chem. 2019, 22. [CrossRef]

21. Wang, L.; Wang, Y.; Wang, X.; Feng, X.; Ye, X.; Fu, J. Small-Sized Mg-Al LDH Nanosheets Supported on Silica Aerogel with Large Pore Channels: Textural Properties and Basic Catalytic Performance after Activation. Nanomaterials 2018, 8, 113. [CrossRef] 
22. Hora, L.; Kelbichova, V.; Kikhtyanin, O.; Bortnovskiy, O.; Kubička, D. Aldol condensation of furfural and acetone over Mgsingle bondAl layered double hydroxides and mixed oxides. Catal. Today 2014, 223, 138-147. [CrossRef]

23. Navarro, R.M.; Guil-Lopez, R.; Fierro, J.L.G.; Mota, N.; Jiménez, S.; Pizarro, P.; Coronado, J.M.; Serrano, D.P. Catalytic fast pyrolysis of biomass over $\mathrm{Mg}-\mathrm{Al}$ mixed oxides derived from hydrotalcite-like precursors: Influence of $\mathrm{Mg} / \mathrm{Al}$ ratio. J. Anal. Appl. Pyrolysis 2018, 134, 362-370. [CrossRef]

24. Bing, W.; Zheng, L.; He, S.; Rao, D.; Xu, M.; Zheng, L.; Wang, B.; Wang, Y.; Wei, M. Insights on Active Sites of CaAl-Hydrotalcite as a High-Performance Solid Base Catalyst toward Aldol Condensation. Catalysis 2018, 8, 656-664. [CrossRef]

25. de Jong, K.P. Synthesis of Solid Catalysts; Wiley-VCH: Weinheim, Germany, 2009.

26. Fotoohi, B.; Kazemzad, M.; Mercier, L. Additive-free synthesis of robust monolithic mesoporous silica support used in catalysis. Ceram. Int. 2018, 44, 20199-20210. [CrossRef]

27. Merckel, R.; Heydenrych, M.; Sithole, B. Pyrolysis oil composition and catalytic activity estimated by cumulative mass analysis using Py-GC/MS EGA-MS. Energy 2020, 219, 119428. [CrossRef]

28. Barnabas, M.; Parambadath, S.; Ha, C. Amino modified core-shell mesoporous silica based layered double hydroxide (MS-LDH) for drug delivery. J. Ind. Eng. Chem. 2017, 53, 392-403. [CrossRef]

29. She, Q.M.; Huang, W.J.; Talebian-Kiakalaieh, A.; Yang, H.; Zhou, C.H. Layered double hydroxide uniformly coated on mesoporous silica with tunable morphorlogies for catalytic transesterification of glycerol with dimethyl carbonate. Appl. Clay Sci. 2021, 55. [CrossRef]

30. Schubert, U.S.; Hüsing, N. Synthesis of Inorganic Materials, 4th ed.; Wiley: New York, NY, USA, 2019.

31. Ko, E.I. Sol-Gel Process. In Preparation of Solid Catalysts; Ertl, G., Knözinger, H., Weitkamp, J., Eds.; Wiley-VCH: New York, NY, USA, $1999 ;$ p. 85.

32. Jose, F.; Nuria, G.; Alba, M.; Pires, E.; Roldan, L. The basicity of mixed oxides and the influence of alkaline metals: The case of transesterification reactions. Appl. Catal. A Gen. 2010, 387, 67-74. [CrossRef]

33. Yu, J.; Fan, G.; Yang, Y. Multi-level three-dimensional Mg-Al layered double hydroxide hierarchical microstructures with enhanced basic catalytic property. J. Colloid Interface Sci. 2014, 432, 1-9. [CrossRef] [PubMed]

34. Chaudhary, R.; Dhepe, P. Upgrading lignin derived monomers over basic supported metal catalysts. Fuel 2021, $306,121588$. [CrossRef]

35. Ahmed, M.; Batalha, N.; Al-Othman, Z.; Yamauchi, Y.; Kaneti, Y.; Konarova, M. Transforming Red Mud into an Efficient Acid-Base Catalyst by Hybridization with Mesoporous ZSM-5 for Co-pyrolysis of Biomass and Plastics. Chem. Eng. J. 2021, $430,132965$. [CrossRef]

36. Arrabito, G.; Domenico, B.; Aurelio, P.; Giuseppe, O.; Andrea, M.; Alessio, M.; Eugenio, P.; Bruno, M.; Pier, G. Layered Double Hydroxides: A Toolbox for Chemistry and Biology. Crystals 2019, 9, 361. [CrossRef]

37. Wang, K.; Zhang, J.; Shanks, B.; Brown, R. Catalytic conversion of carbohydrate-derived oxygenates over HZSM-5 in a tandem micro-reactor system. Green Chem. 2014, 17, 557-564. [CrossRef]

38. Ben, H.; Wu, F.; Wu, Z.; Han, G.; Jiang, W.; Ragauskas, A. A Comprehensive Characterization of Pyrolysis Oil from Softwood Barks. Polymers 2019, 11, 1387. [CrossRef]

39. Anoop, E.; Ajayghosh, V.; Nijil, J.; Cm, J. Evaluation of pulp wood quality of selected tropical pines raised in the high ranges of Idukki District, Kerala. J. Trop. Agric. 2014, 52, 59-66.

40. Chen, X.; Zhang, K.; Xiao, L.; Sun, R.; Song, G. Total utilization of lignin and carbohydrates in Eucalyptus grandis: An integrated biorefinery strategy towards phenolics, levulinic acid, and furfural. Biotechnol. Biofuels 2020, 13, 1-10. [CrossRef] [PubMed] 